\title{
The Globally Competent Engineer: Working Effectively with People Who Define Problems Differently
}

GARY LEE DOWNEY

Department of Science and Technology in Society

Department of Engineering Education

Virginia Polytechnic Institute and State University

JUAN C. LUCENA

Division of Liberal Arts and International Studies

Colorado School of Mines

BARbara M. Moskal, Rosamond PARKHURST

Department of Mathematical and Computer Sciences

Colorado School of Mines

Thomas Bigley, Chris Hays, Brent K. Jesiek, LiAM KELLY, JONSON Miller, SHARON RUFF

Graduate Program in Science and Technology Studies

Virginia Polytechnic Institute and State University

JANE L. LEHR

Department of Education E Professional Studies

King's College London

AMy Nichols-Belo

Department of Anthropology

University of Virginia

\section{AbSTRACT}

This paper offers and tests an approach to conceptualizing the global competency of engineers. It begins by showing that the often-stated goal of working effectively with different cultures is fundamentally about learning to work effectively with people who define problems differently. The paper offers a minimum learning criterion for global competency and three learning outcomes whose achievement can help engineering students fulfill that criterion. It uses the criterion to establish a typology of established methods to support global learning for engineering students. It introduces the course, Engineering Cultures, as an example of an integrated classroom experience designed to enable larger numbers of engineering students to take the critical first step toward global competency, and it offers a test application of the learning criterion and outcomes by using them to organize summative assessments of student learning in the course.

Keywords: global competency, culture, assessment

\section{INTRODUCTION}

Educational initiatives are currently underway in Australasia, Europe, Latin America, and the United States to better prepare engineering students to function effectively in global environments. Some basic questions that every such initiative must face include: What does it mean for engineers to become globally competent? What counts as global work in engineering? What forms of knowledge or sets of capabilities prepare engineering students for such work? Finally, and most importantly, what sorts of learning experiences are helpful in gaining such knowledge and capabilities?

The analysis presented in this paper addresses the above questions in the following ways. First, it introduces the concept of global competency for engineers and shows that the key achievement in the often-stated goal of working effectively with different cultures is learning to work effectively with people who define problems differently than oneself. Second, it offers a minimum learning criterion for the global competency of engineers and a set of three learning outcomes whose achievement can help engineering students fulfill that criterion. Third, it uses this criterion to establish a typology of established methods in the United States and Europe to support global learning for engineering students as well as to briefly characterize each method. Fourth, it introduces the course, Engineering Cultures, as an example of a type of classroom experience that can enable larger numbers of engineering students to take the critical first step toward global competency. Finally, the paper offers a test application of the learning criterion and learning outcomes by using them to conduct and present summative assessments of student learning in the course at both Virginia Tech (VT) and the Colorado School of Mines (CSM), and to discuss the strengths and limitation of this first-step approach in the context of other initiatives and the general problem of global competency.

\section{GlobAL COMPETENCY FOR ENGINEERS}

Developing a concept of global competency requires one to address at least two distinct sets of questions. The first might be described as the problem of cultures. The second concerns specifically what achieving global competency adds to learning in engineering education [1-3].

\section{A. The Problem of Cultures}

In the United States, the problem of global competency for engineers is often presented as a problem of engaging people from 
different cultures. For example, Swearengen et al. hold that "to thrive, future engineers will have to be able to work productively with radically different cultures"[4]. At Old Dominion University, the cluster of courses designed to help prepare engineers for global work includes "Communications across Cultures" [5]. The Global Perspective Program at Worcester Polytechnic Institute, which stands out by providing an international experience for the majority of its graduates, includes as a key evaluation criterion for student reports, "Exposure to Global Issues and/or Foreign Cultures" [6-8]. The Program in Global Engineering at the University of Michigan includes among its main objectives "to appreciate people, culture, and engineering practices of other nations" and "to develop students' capacities for intercultural sensitivity" [9]. Furthermore, Eljamal et al. assert that among the most important outcomes of international experiences for engineering students are "an appreciation for other cultures" and "development of a multicultural perspective" [9].

One general reason for this emphasis on working with different cultures, as explained by U.S. researchers in cross-cultural communication, is that people in the U.S. tend to highlight similarities across cultures while minimizing differences. For example, Milton Bennett, founder of the Intercultural Communication Institute, reports that he "observe[s] in most classroom and workshop environments that difficulties in learning the concepts and skills of intercultural communication are nearly always attributable to a disavowal of cultural difference, not to a lack of appreciating similarity" [10]. Similarly, at the University of Michigan, Mayhew et al. conclude from a pre-test of more than 100 engineering students undertaking intercultural training that "Students minimize differences and focus on the similarities between different cultures" [11].

An important caution to recognize and keep in mind in developing approaches to global learning is that one key feature of a globalizing world is that it is increasingly difficult and, indeed, problematic to characterize people as members of different cultures. Characterizing a person as a member of a culture typically depends on the assumption that cultures are membership groups that are discrete, distinct from one another, and have boundaries that overlap roughly with the boundaries of countries. Thus, someone who grew up in a given country presumably is a member of that country's culture and, thus, has a cultural identity defined more or less in national terms.

But this assumption is challenged by the rapidly increasing mobility of populations across national borders and high level of diversity within them. As a member of the Oregon wine industry recently put it, "Everyone seems to be everywhere these days." Such mobility means that people increasingly have identities that locate or root them in more than one country. Individual cases become quite complicated, especially as people spend substantial periods of their lives in countries outside the country of birth. As a result, the idea of cultures as membership groups overlapping with nation states, which is a holdover from the mid-twentieth century, becomes too simplistic to characterize differences among people in the present. If people cannot easily be described as members of single cultures, then equating cultures with countries and classifying residents in a given country as members of its culture is inappropriate.

How then should we think about the learning objective for engineers of, as Swearengen et al. state, "work[ing] productively with radically different cultures"? The key point has to do with countries. Statements about the benefits of global learning for engineering students typically locate those benefits in encountering and coming to understand engineers and other potential co-workers who are raised, educated, and living in countries other than their own. The innumerable calls over the past decade for global learning for engineers and the wealth of emerging initiatives in international education demonstrate clearly that people who are raised, educated, and living in different countries, especially engineers, constitute a key target group. Although such people comprise only one subset of the configurations of national identities and experiences that engineering students are likely to encounter on the job, their special educational status is an indicator of the key, defining element in the goal of working productively with different cultures, i.e., learning to effectively engage understanding and ways of thinking about engineering work that differs from your own. Even if other countries do not have single cultures, they nonetheless provide high-probability sites for encountering unfamiliar ways of thinking about engineering work.

\section{B. What Global Competency Adds to Engineering Education}

Learning to engage understanding and ways of thinking about work that differs from your own would seem to be an obvious objective for any type of employment in a globalizing world. However, it has special significance for engineering education because of the core focus in engineering on technical problem solving. In particular, engaging ways of thinking and understanding that differ from your own can refer either to ways of solving or of defining problems. Consider each of these in turn.

Engineering education in the United States from the 1960s through the mid-1990s tended to place central focus on education in the engineering sciences. Although significant variations existed across disciplines, departments, and schools, one dominant pattern included students completing hundreds of exercises in engineering science courses. In the process, they learned and practiced the view that the first key step in engineering problem solving was to draw a boundary around the problem [12]. Indeed, such was a common statement that engineers made about their work, as the former chief-of-staff to President Reagan, John Sununu, stated, "[Y] ou've got to define the problem clearly before you can start working on the solution" [13]. Drawing a boundary around a problem was the essential step in learning the so-called "engineering method" in engineering science classes because it enabled students to draw on the mathematical theories of the engineering sciences to find a solution. The engineering method was regularly taught as a five-step process: "Given, Find, Equations, Diagram, Solution."

An unintended consequence of this emphasis was that, while coming to master mathematics-based engineering analysis, students were also practicing the view that engineering problem solving led only to right or wrong answers. Students who completed hundreds of problem sets on graded homework as well as hundreds of individual problems on graded exams were receiving intensive training in dividing the world of problem solvers into two parts, those who drew the boundary in the appropriate way and those who did not. Those who did draw the boundary the same way became capable of being "right" and those who did not were, by implication, "wrong." In the process, those who were right thereby demonstrated that they had more ability than those who were wrong. 
In Europe, engineers were also learning to value the technical dimensions of engineering when solving problems; however, the manner in which they approached problem solving varied from country to country. While important differences have emerged and persist within countries, it is possible nevertheless to identify significant national patterns that indicate dominant standards of value. For example, in France engineering students were learning that the highest value was placed on mathematical derivations from first principles even if they found ways of avoiding or resisting its force, whereas in the United Kingdom students at all levels were being challenged to recognize the foundational importance of practical knowledge in problem solving. At Fachochschulen in Germany, students regularly encountered the view that no quality work in engineering can take place without first gaining an intrinsic feel for precision [14]. Even in those cases in which students did not come to divide problems solvers into the right and the wrong, they were certainly learning to divide problem solvers into better and worse. That is, experiencing curricula that were almost wholly technical in content, students accepting the challenges learned to value specific strategies for solving problems that often differed from those emphasized in other countries.

Developing a predisposition to expect worlds of problem solvers to be divisible into right or wrong or better and worse is problematic as engineering increasingly involves working alongside engineers from different backgrounds. Working with engineers who solve problems differently has become a regular condition of engineering work.

Over the past decade, activist engineering educators in the United States have sought to reform engineering education by making it clearer to students that they can solve engineering problems in more than one way. The most extensive U.S. activities have focused on increasing the amount of design content in the curriculum, including the introduction of design exercises into more courses, shifting from "design to specifications" to more open-ended problem solving, and increasing attachments to industry [15-17]. Meanwhile, European activities have focused on preparing graduates for career mobility by restructuring degrees, expanding the non-technical contents of engineering curricula, and developing a system of student exchanges between countries [17-22]. Motivated by the Bologna Declaration to work toward a European system of engineering formation, engineering educators from different countries have worked hard to learn about and document different approaches to problem solving. Australasian and Latin American engineering educators are closely watching these developments and beginning their own reforms [23].

Exercises in global learning that place students into contact with engineers or engineering students in other countries contribute directly to this important movement to demonstrate that engineering problems can be solved in more than one way, but they also carry the learning one step further. For example, in a 2001 interview, Ruth Walters, a British engineering student at the University of Manchester, described her surprise at learning that the French exchange student in her civil engineering class solved a homework problem by deriving the answer mathematically from first principles while she and fellow students had solved it using graphical methods [24]. Beyond coming to appreciate that the problem could, in fact, be solved different ways, she found this experience to provide crucial insight into the visiting student's preference for mathematical derivation in engineering work, and indeed her own preference for graphical methods. It was both clear and important that neither was willing or easily able to adopt the practices of the other.

Given existing educational initiatives on solving problems differently, the additional competency gained from effectively engaging people from other countries is to learn to work with people who define problems differently. Engineering problems do not solve themselves; they are always solved by people. Once people are introduced to the problem-solving situation, it takes on human as well as technical dimensions, including relevant dimensions of work and career. For example, successfully solving an engineering problem in the United States often includes demonstrating individual ingenuity, drive, and initiative, while in Japan the successful solution of an engineering problem often includes demonstrating instead that one is fulfilling obligations to some greater whole $[25,26]$. What engineers come to include in problem solving depends upon who engineers are and what counts as the wider significance of their work, issues whose dominant forms vary in patterned ways from country to country. For example, as Downey and Lucena elaborate, helping France advance by increasing social order and working toward an ideal future state of perfection has helped legitimize an emphasis on mathematical theory [14]. Meanwhile, helping Britain advance through improvements in material comfort has helped legitimize an emphasis on design and practical knowledge, and helping Germany advance by emancipating geist, or shared mind/spirit, has helped legitimize an emphasis on technological theory and practice to achieve precision. To the extent engineering education concentrates only upon the technical dimensions of the process, it leaves out the important human dimensions, defining these as extraneous and irrelevant and inhibiting engineers from learning how to address them.

One way of acknowledging the human dimensions of engineering work is to recognize that engineering work always depends upon the activity of problem definition in collaboration with others [27]. In carrying out their work, engineers necessarily negotiate and renegotiate the definitions of technological problems both among themselves and with non-engineers. Since problem definition takes place, or at least begins, before problem solving, collaboration among people who define problems differently occurs prior to the technical work of problem solution and involves more than the specification of requirements.

In the United States, the traditional engineering method, which is still taught regularly in engineering science courses, offers no method or mechanism for working with people who draw boundaries around problems in different manners. Also, with some notable exceptions, the important curricular reforms that alert students to different ways of solving problems tend not to address the human dimensions of collaborative problem definition, including the different meanings that technical work has for lives and careers. Addressing and resolving differences over problem definition remains an under-addressed issue. In Europe, the efforts to restructure degrees and expand class experiences in the humanities and social sciences typically do not address the issue of defining problems in collaboration with others.

In sum, the achievement of global competency depends critically on developing the ability to work effectively with people who define problems differently than oneself, including both engineers and non-engineers. Interactions with people from other countries are valuable because they are most likely (a) to draw boundaries around problems in different ways and (b) to judge problems to have 
distinct implications for their lives and careers. The key benefit in the ideal of learning to work productively with other cultures thus involves going beyond recognizing that engineering problems can be solved in different ways to understanding that problems can be defined in different ways and mean different things to people holding different perspectives. While it no longer makes sense to assume that each person is a member of one culture whose boundaries coincide with those of a country, it does make sense for engineering students to gain experiences with people who are participating in, responding to, and/or challenged by cultural perspectives that differ from their own, regardless of how these differences might map across or within countries. Finally, by learning to work effectively with people who define problems differently, engineering students are also working to make their education more complete by recognizing and learning to grapple with the human dimensions of engineering work, which stand alongside technical dimensions as essential core features.

\section{A LEARNING CRITERION FOR GLOBAL COMPETENCY}

Drawing on this discussion, the proposed learning criterion for the global competency of engineering students is as follows:

\section{Through course instruction and interactions, students will acquire the knowledge, ability, and predisposition to work effectively with people who define problems differently than they do.}

Learning criteria are broad statements designed to guide the development of intended outcomes in student learning. Descriptions of learning outcomes then guide the creation and assessment of courses and curricula that are designed to help students meet or fulfill the criteria. The proposed student learning outcomes for the global competency of engineers are displayed in Figure 1.

The learning outcomes point to the importance of learning about and working with people from different countries as a practical strategy for learning how to work effectively with people who define problems differently. The first component of the criterion and proposed learning outcome focuses upon knowledge. A successful global learning experience enables students to gain a factual understanding of how engineers and non-engineers from different countries may differ in their technical work, including how they draw boundaries around that work and what it means to their lives and careers.

The second component/outcome is ability. A globally competent engineer is someone who has progressed beyond what Shuman et al. call "awareness skills," which are achieved through the acquisition of knowledge, to achieve "process skills," which include a combination of intellectual and behavioral capacities to integrate new forms of knowledge into everyday practices of engineering work [28]. Crucially, the achievement of process skills requires practice.

The third component/outcome, predisposition, is more difficult to identify and assess, yet it may be the most important of the three. All learning activities include a dimension of training in the sense that they prepare learners to interpret, address, and engage aspects of the world in particular ways [29, 30]. In this context, the term "predisposition" names not inherent features of character or temperament but refers to learnable tendencies or patterned actions that are public and, hence, observable by others. A predisposition to treat co-workers from other countries as people who have knowledge and value is an outcome of learning that is distinct from knowledge and ability and yet can serve as a crucial indicator of likely future actions.

The key element in this learning criterion is the descriptive image it presents of engineers working effectively with people who define problems differently than they do. The learning outcomes accept the view that acquiring knowledge and experience with people from other countries, especially with individuals who are likely to be coworkers and/or affected by your work, offers one clear, reasonably reliable pathway toward the achievement of global competency. It is difficult to imagine many circumstances in which the performance of global competency would not include working effectively with people from countries other than your own. The learning criterion does not specify working effectively with different cultures because it assumes that people who are raised, educated, and living in other countries are likely to define technical problems in different ways even if their own identities are multinational in some significant sense. Also, it is important that the criterion refers to both engineers and non-engineers, for effective engineering work in global contexts includes substantial contact and effective work with non-engineers.

\begin{tabular}{ll}
\hline Learning Criterion & $\begin{array}{l}\text { Through course instruction and interactions, students will acquire the } \\
\text { knowledge, ability, and predisposition to work effectively with people } \\
\text { who define problems differently than they do. }\end{array}$ \\
\hline Learning Outcomes & $\begin{array}{l}\text { 1. } \\
\text { Students will demonstrate substantial knowledge of the similarities } \\
\text { and differences among engineers and non-engineers from different } \\
\text { countries. }\end{array}$ \\
2. $\begin{array}{l}\text { Students will demonstrate an ability to analyze how people's lives } \\
\text { and experiences in other countries may shape or affect what they } \\
\text { consider to be at stake in engineering work. }\end{array}$ \\
3. $\begin{array}{l}\text { Students will display a predisposition to treat co-workers from } \\
\text { other countries as people who have both knowledge and value, } \\
\text { may be likely to hold different perspectives than they do, and may } \\
\text { be likely to bring these different perspectives to bear in processes } \\
\text { of problem definition and problem solution. }\end{array}$
\end{tabular}

Figure 1. Minimum learning criterion and learning outcomes for global competency. 


\section{TYPOLOGY OF METHODS FOR ACHIEVING GLOBAL COMPETENCY}

This section presents a conceptual typology of educational methods for helping engineering students take steps toward the achievement of global competency. The typology includes international enrollment, international project, international work placement, international field trip, and integrated class experience. Drawing on the three learning outcomes, the typology introduces each method, identifies variables that distinguish different examples of the method, and briefly articulates the dimensions of knowledge, ability, and/or predisposition that the method seeks to help students develop. In all cases, as Shuman et al. explained with regard to engineering ethics, a demonstration of global competency in learning situations offers no guarantee that such learning will carry over into practice [28]. However, it seems likely that offering no such learning opportunities is a sure way to inhibit the practice of global competency among engineers.

It is important to recognize that while in Europe the development and administration of methods for achieving global competency have often been developed and managed under the auspices of the European Union, in the United States these methods have tended, with some notable exceptions, to emerge from efforts of faculty members or administrators working in isolation or in smallscale collaborations. In the U.S. context, these individual pioneers of global education for engineers have designed, implemented, and, when possible, scaled up site-specific programs to fit local capabilities, interests, and opportunities. They typically have had to cobble together resources to develop demonstration projects, achieve credibility, and work to become institutionalized in local educational infrastructures. In recent years, the National Science Foundation has added an important external source of support and legitimacy [31].

One implication of the American "custom-designed" approach to global competency is that no conceptual typology can successfully capture all the features that enable individual programs to work well. The published literature on these efforts is now extensive. Some good entry points include references [28], [32], and [33]. But the goal here is not to classify or assess existing programs. Rather, the exercise of constructing a conceptual typology of learning activities can prove helpful in assessing more generally where global learning for engineering students stands at present as well as highlighting possible areas for expanded effort.

\section{A. International Enrollment}

The method of international enrollment is designed to lift students out of the comfort of familiar circumstances and place them in unfamiliar and distinctly foreign contexts. At a formative point in their careers, students are ideally surrounded by actions and signals they do not recognize and, hence, are challenged to understand. They are further challenged to engage these differences without the immediate support of families or peer groups. International enrollment is designed to be a solitary experience. It includes both study abroad, in which a student enrolls in an institution located in another country, and international exchange, in which countries formally exchange students.

Key variables distinguishing examples of international enrollment include: (a) length of time in the foreign country, often ranging from a summer to a year; (b) whether or not the experience includes education and daily life in a foreign language; (c) type of housing and after-hours learning, ranging from sharing dormitory space with other visiting students to living with a host family; and (d) whether the enrollment includes engineering classes.

International enrollment is the highest-profile method for building global competency because it seeks to go beyond placing a student in contact with people from other countries to making the student one of them, if only temporarily. The motivating image is that of "immersion" in a totally foreign culture, in which one learns enough to approximate the knowledge, abilities, and predispositions of a native. However, because becoming a student in another country does not involve giving up one's identity in the home country, the ideal of immersion is, in principle, impossible to achieve. Students do not trade one identity for another, and previous dimensions of a student's identity remain intact even if altered by the experience. Also, people in the host country have no illusions that the student is more than a temporary visitor, an assessment that is reinforced by the student's participation in tourism. Although not working with engineering students, Dolby persuasively argues that the most important encounter in a study abroad experience is actually with oneself. That is, such experiences force students to confront and examine their understandings of themselves and the perspectives they have gained while being raised and educated in their home countries as they encounter people who likely understand those home countries in contrasting ways [34].

The key form of knowledge from international enrollment is first-hand understanding of exemplary student trajectories, perspectives, and lives in the host country. By interacting with students who are likely seeking to fulfill a range of career objectives, the visiting student is able to observe directly student struggles to define and pursue their ambitions. The student is able to learn what counts as ambition, what constitutes desirable and undesirable pathways, and how trajectories through engineering relate to trajectories in other areas. Also, depending on whether or not the visiting student is enrolled in engineering courses, he or she may gain some insight into what is emphasized or not emphasized in technical engineering work.

Defined narrowly, international enrollment does not include the activity of engaging host students as co-workers. Hence, it may provide little experience in analyzing how people's lives and experiences may shape or affect what is at stake in engineering work. However, because building relations with fellow host students can facilitate direct observation of students managing relations between schoolwork and life issues, the experience can facilitate an enhanced ability to infer at least some of the issues that might be at stake in engineering work in that country and why.

By gaining first-hand experience and personal knowledge of peers who likely think about their lives and work in different ways, international enrollment promises to ground a predisposition that people who think differently about engineering work nonetheless are likely to have value and worth. Such is, of course, not a guaranteed outcome. Some students return home with a sharpened hierarchical view of the home country in relation to the host.

\section{B. International Project}

The international project extends an existing component of engineering curricula, the advanced-level or capstone project, to work in another country. In contrast with international enrollment experiences, students go beyond interacting with classroom peers to have collaborative work experiences with people who have been raised, 
educated, and living in the host country. A distinguishing feature is shared responsibility to bring a project to a successful conclusion.

Key variables include whether or not the project: (a) has clients and/or co-workers in the host country; (b) includes as clients and/or co-workers engineers from the host country and/or other countries; (c) is defined by clients, faculty, and/or students; and (d) requires a presentation and/or report to clients.

Although students may gain a lesser degree of knowledge about the lives and careers of co-workers from the host country than they might gain from fellow students via international enrollment, they do acquire specific first-hand knowledge about how actual coworkers from the host country define and solve technical problems. Students directly experience the challenges of engaging people, typically understood as clients, who may think about the project in different ways and, thus, add dimensions to decision making that are both unexpected and crucial to success. The international project thus can serve as a lesson in the open-endedness of engineering project work, especially in collaborative problem definition. Also, to the extent the project experience calls attention to and emphasizes different engineering perspectives within the project team itself, it can also provide an important experience in considering and managing multiple stakeholders in engineering problem definition.

In contrast with international enrollment, the international project method typically has students working in teams and remaining clearly identifiable as outside visitors. At the same time, the concrete knowledge gained through shared work in defining and solving a technical problem enables participants to go beyond predicting what sorts of issues might be at stake in engineering work in that country to actually developing strategies for defining and solving a technical problem in a foreign context.

The high level of commitment that is required to complete a successful project typically depends upon project participants developing the predisposition that clients and other co-workers bring perspectives that have value and worth. Actually bringing a project to completion can powerfully affirm the instrumental importance of this predisposition.

\section{International Work Placement}

The international work placement typically involves traveling to another country in a paid or unpaid internship or temporary position in a private company that relies on engineers. Like the international enrollment, the international work placement is designed to be a solitary experience, for the student joins the company or organization as an employee. Like the international project, the international work placement challenges the student to work directly with people who are raised, educated, living, and working in the host country. As such, it functions as an apprentice experience not only in the development but also in the performance of global competency.

Key variables in international work placement include: (a) the length of time of the placement, often ranging from a summer to a year; whether it (b) is with a foreign-owned firm; (c) involves travel to another country; (d) is a paid position designed to lead to longterm employment; and (e) leads to the development of close personal relations with co-workers.

In international work placement, students gain first-hand knowledge of how engineering work is carried out in a foreign context, including both problem definition and problem solution. Students have the opportunity to acquire substantial organizational knowledge about the operations and context of the firm, the re- sponsibilities and routine activities of various positions within the firm, and the sorts of perspectives that people who occupy those positions have about the organization and its work.

The international work placement challenges students almost immediately to engage different ways of defining and solving problems. It gives students the opportunity to test directly how they will respond to the demands of engineering work in foreign contexts. The extent to which they develop the important ability to assess what motivates the different perspectives they encounter depends significantly upon the depth of relationships they establish with co-workers and the level of commitment to the experience they demonstrate.

The international work placement should maximally support the development of a predisposition to expect that differences among engineers and co-workers from different countries have value and worth. In the best of circumstances, the student develops both routines for such work and confidence in those routines. As an apprenticeship for global competency, the work placement may prepare the student directly to continue the experience in full-time employment.

\section{International Field Trip}

This more limited method refers to the relatively short, e.g., twoweek, trip to another country, organized to be relevant to the education of engineering students. Typically organized by a faculty member, the international field trip provides students with an introductory encounter with a foreign context within the relative safety of the group and familiar model of the tour. In contrast with the above methods, it includes more limited contact with people from other countries but nonetheless provides an assortment of first-hand experiences.

Significant variables in the international field trip include: (a) the level of connection to other course experiences at the home institution; (b) the type and content of research and writing responsibilities for participating students; and (c) the number and types of contacts that are made with people in the host country.

The main knowledge benefit of the international field trip is that it enables students to gain initial configurations of factual knowledge about engineers and engineering work in other countries and, possibly, to observe directly alternative ways of thinking about engineering work. In contrast with the previous approaches, the international field trip is unlikely to provide students with the ability to analyze how people's lives or experiences in other countries may shape or affect what they consider to be at stake in engineering work. However, it does prepare participating students to formulate and ask such questions and may embolden them to do so. Finally, by providing students with an introduction to foreign contexts in a relatively safe environment, the international field trip could ground development of a predisposition to expect that engineering perspectives in other countries may have value and worth.

\section{E. Integrated Class Experience}

The integrated class experience is an at-home effort to initiate students on the path to global competency in ways that fit their standard curricula. Often including such activities as introductory education in the language, customs, history, and government of the country in question. The integrated class experience is frequently prefatory to or collateral with one of the previous methods, which involve international travel. It sometimes provides a substitute for international travel, such as in the electronic interactions of international design teams. Key variables include: (a) the specific intellectual 
content of the experience; (b) whether it is a course or extra-curricular program; (c) whether it is connected directly to engineering curricula; (d) whether it involves first-hand interactions with people from other countries; and (e) whether it is linked to another method involving international travel.

In most cases, the integrated class experience grounds student progress toward the learning outcomes via other methods by providing background knowledge about life in other countries. When it works well, such background knowledge reduces student confusion and misunderstanding while in the host country and increases the rate at which students can advance toward a higher level of global competency. To the extent the integrated class experience engages students in simulations of the foreign experience or provides opportunities for first-hand interactions, they can help students take the first step toward establishing the ability to analyze how people's lives or experiences may shape or affect engineering work. The extent to which they are able to instill a predisposition to expect that people who define problems differently will have knowledge and value typically depends upon the extent to which students become interested in the forms of knowledge offered or, in the case of first-hand interactions, the perspectives of participants from other countries.

To date, the most significant challenge to the methods of international enrollment, international project, international work placement, and international field trip is to increase their sheer scale of participation. At present, fewer than three percent of engineers in the U.S. seek international enrollments [35], and in Europe only one percent of all European engineering students participate in ERASMUS programs [36]. In both cases, participation in the methods of international project, work placement, and field trip likely does not increase this amount to more than five or six percent. Given limited participation in these experiences, it makes sense to seek ways of expanding integrated class experiences, both to provide substitute experiences for those students who cannot afford or who are not inclined to undertake international travel, and to further enhance the learning of those who do travel.

\section{TAKing The First STEP: EngIneEring Cultures}

A critical first step for students to be able to work with people who define problems differently is to have concrete knowledge about real cases and experience recognizing that such differences do not reflect inferior quality. One potentially promising approach is to use part of the existing humanities/social sciences section of engineering curricula to develop courses oriented to global competency. Not only does this require minor adjustments to the curriculum but also useful innovations may be scalable across engineering institu- tions and serve to fuel greater participation in methods that require travel. At Virginia Tech and Colorado School of Mines, we have developed and tested a one-course method that is designed to enable large numbers of students to take the first step toward global competency by achieving a record of accomplishment in all three learning outcomes: knowledge, ability, and predisposition.

\section{A. Course Outcomes}

Engineering Cultures seeks to launch students on paths toward global competency in three ways. First, students learn about the historical emergence and contemporary states of the engineering profession in different countries. Second, they practice interacting with and engaging engineers from other countries in simulated encounters, including a method for collaborative problem definition. Third, when the course works well, students develop a predisposition to value the contributions of others to engineering work by coming to understand and articulate the perspectives toward engineering work they hold themselves as engineering students.

Figure 2 specifies the three learning outcomes of the course. Note that these outcomes deviate somewhat from the learning outcomes in Figure 1. The reason for this is that Engineering Cultures is designed to be a first step in progressing toward global competency rather than the only step. Fully attaining the outcomes presented in Figure 1 cannot be expected through a one-course intervention at the home institution.

Learning Outcome 1: The first course outcome, which focuses on knowledge, differs from the first learning outcome for global competency in that it focuses specifically on similarities and differences among engineers in different countries by tracing the development of dominant national patterns in engineering knowledge and engineering work. It does not investigate non-engineers and it provides only brief introductions to subordinate movements and points of view. In achieving this outcome, students do come to understand, within a given country, dominant images of what it means to be an engineer, including the types of knowledge engineers are likely to value.

Engineering Cultures surveys through discrete, substitutable modules the emergence of engineering as a professional practice in different countries. Modules in the course examine engineers in France, U.K., Germany, Japan, Soviet Union/Russia, and the U.S. Efforts are currently underway to create similar modules on engineers in Brazil, China, Colombia, Egypt, India, Korea, Mexico, and Taiwan. Each module addresses four questions.

(a) How did the nation state evolve? Addressing the first question involves identifying those geographical, historical, political, and demographic dimensions of the country that provided the context for the emergence of engineers. An important issue to consider in each case is what has counted as dominant ideas of national progress, for
Learning Outcomes
1. Students will demonstrate substantial knowledge of national patterns in engineering knowledge and engineering work.

2. Students will demonstrate an ability to analyze how national differences are important in engineering work.

3. Students will demonstrate a predisposition to engage engineers from other countries as co-workers who have knowledge, value, and points of view, and to expect to accommodate their own perspectives to those of other engineering problem solvers.

Figure 2. Learning outcomes in Engineering Cultures. 
these ideas have played a key role in shaping dominant patterns of engineers and engineering knowledge in that country. For example in France, the dominant idea has been that progress is achieved through activities that enhance social order and support the advancement of society toward an ideal future state of perfection. The emergence of this idea can be traced back to the development of an absolutist state during the seventeenth and eighteenth centuries. By contrast, the early development in England and the U.K. of a parliament with strong representation from Commoners provides evidence of the dominant British idea of progress as improvements in material comfort over the past, with material comfort defined in terms of distance from manual labor. In Germany, the country has long been a collection of diverse states and national coherence has been emphasized as a significant problem. Efforts to advance the German nation have focused upon the emancipation of German geist, which is the distinctive mix of mind and spirit that is thought to be shared by all Germans [14].

Another important dimension is the influences that countries have had on each other. For example, former colonies of Britain and France have unusual mixes of influences on engineers from both colonial and domestic sources. Understanding the emergence of engineering in the United States, for example, requires understanding the unique relationships that developed between early efforts to scale up British and French ideas and a novel, emergent national commitment to progress as improvements in the production of low-cost goods for mass consumption [37]. Likewise, the case in Egypt includes historically distinct influences from French, British, German, Soviet, and American sources mixed with indigenous yearnings to recreate the past glory of Egyptian civilization and work toward an economic union of Arab states.

(b) How have engineers emerged in this country? In order to understand how engineers emerged in each country, Engineering Cultures considers the following questions within each module: What has it meant to be an engineer? What sorts of knowledge have engineers valued? How and why has a given national emphasis in engineering changed over time?

Pursuing these questions trains students to anticipate and be able to understand differing patterns of social position and status among engineers in different countries. For example, while the most elite French engineers have used their mathematical capabilities as a steppingstone to work in government, which is considered to be the highest-ranked occupation in the country, the majority of engineers work in lower status positions in industry. In Germany, engineers emerge in two distinct patterns from what are today called the technical universities and universities of applied science. The challenge in each case is to document dominant patterns while also pointing out differences, showing how such patterns have emerged and served as standards of value against which individual engineers have measured themselves and their careers.

(c) What is a typical career trajectory for an engineer? Following typical career trajectories for engineers requires examining both what has emerged to count as engineering education and where engineers have typically worked. Differences within a given country can be significant. For example in Mexico, engineering training at Universidad Nacional Autónoma de México provides a key pathway to highstatus positions in government; training at Monterrey Tech, on the other hand, is a pathway to high-status positions in private industry [38]. To this day, students within Mexico must carefully consider their career ambitions before they enter a particular college.
By understanding such differences as these, students learn to ask intelligent questions about co-workers and make reasonable predictions about their career goals and desires. Thus, for example, knowing that the most elite French engineers are tracked into government may provide insight into a French engineering co-worker whose career has been wholly in private industry. Students learn to speculate that the engineer may see himself or herself as an activist seeking higher status for industry within France, may be seeking to leave France and develop a stronger international identity, or may simply have accepted a lower-status career trajectory in order to secure a stable income and perhaps higher class mobility for his or her children.

(d) What are key emerging trends for engineers and engineering? Following key emerging trends typically involves exploring how the country under study is grappling with images of industrial competitiveness and what counts as globalization. Pursuing this question prepares students to anticipate more general concerns, fears, and senses of opportunity among co-workers. For example, where responding to globalization may challenge French engineers to seek ways of placing higher value on activities in private industry, German engineers may find themselves struggling to maintain a commitment to engineering precision while having to compete more on the basis of low price.

Learning Outcome 2: The second outcome, developing the ability to analyze how national differences are important in engineering work, is designed to help students anticipate and recognize the range of different perspectives they are likely to encounter on the job. A conceptual feature of Engineering Cultures that has proven helpful is that the course treats a culture not as something shared by all the members of a given group but rather as a set of "dominant images" that challenge people in a given location with their meanings and expectations. The purpose of this emphasis is to enable engineering students to recognize and analyze differences among people responding to a given culture as well as differences in cultures. While the course focuses specifically on dominant images of progress that become associated with countries, this approach also calls students' attention to other sorts of dominant images they will encounter on the job, including within companies.

Following from the previous discussion, students in Engineering Cultures learn that contrasts in what has counted as engineers and engineering knowledge in different countries can have implications for practices of problem definition in at least two ways. One way is that the scope of what counts as a relevant problem for engineers may vary from place to place. It matters, for example, if mathematics is valued highly, if low cost is essential, or if precision is a defining value. A second is that particular types of tasks may have diverse implications for engineering career paths in different countries. For example, the German engineer leading an effort to accelerate the design process could either, depending on the circumstances and outcomes, be revered by co-workers as protecting German industry or reviled as undermining German engineering. Since engineers have unique life histories and may not fit dominant national patterns, the effective engineering worker must sort out the particularities of each case. Engineering Cultures seeks to assist students in developing this competency, in part by analyzing their own lives.

Engineering Cultures relies heavily upon oral discussions and written exercises, especially role-playing exercises, to help students practice adopting different perspectives. Figure 3 offers an example of a homework assignment involving European engineers:

Other examples include asking students to imagine themselves as Japanese engineers working with Americans on a given project, 
Homework: For this assignment, draw on readings and class discussion about engineers in Europe and construct a three-way dialogue. The participants in the dialogue include representatives from two of the three countries and yourself. Assume the others are classically trained in their respective countries. Then, take some time and discuss amongst yourselves the differences in images you all share, how these might have come about, and especially how the other two might be impacting you right now.

Feel free to include, in absentia, the third country's engineering tradition (but don't be too harsh on someone who isn't there to defend him/herself). Be as creative as you wish to be in setting the scene and developing the characters, but please limit your conversation to two pages.

Figure 3. Sample homerwork assignment.

describing likely conflicts among Mexican engineers trained at three different types of institutions, and drafting a historically-informed poem that captures the dreams of early Soviet engineers. In every case, the emphasis is on connecting dimensions of national identity to some specifics of engineering work.
Learning Outcome 3: Achieving outcome 3 tends to be the most difficult for students. This outcome requires moving beyond the recognition and sophisticated analysis of differences to the actual practice of formulating alternative responses, depending upon the particulars of the case. The Engineering Cultures curriculum and

Step 1 Identify each perspective that is involved in the decision you face. Remember that problems often mean different things in different perspectives. Relevant differences might include national expectations, organizational positions, disciplines, career trajectories, etc. Consider using the mnemonic device "Location, Knowledge, and Desire."

Location: Who is defining the problem? Where are they located or how are they positioned? How do they get in their positions? Do you know anything about the history of their positions, and what led to the particular configuration of positions you have today on the job? Where are the key boundaries among different types of groups, and where are the alliances?

Knowledge: What forms of knowledge do the representatives of each perspective have? How do they understand the problem at hand? What are their assumptions? From what sources did they gain their knowledge? How did their knowledge evolve?

Desire: What do the proponents of each perspective want? What are their objectives? How do these desires develop? Where are they trying to go? Learn what you can about the history of the issue at hand. Who might have gained or lost ground in previous encounters? How does each perspective view itself at present in relation to those it envisions as relevant to its future?

Step 2 As formal problem definitions emerge, ask "Whose definition is this?" Remember that "defining the problem clearly" may very well assert one perspective at the expense of others. Once we think about problem solving in relation to people, we can begin to see that the very act of drawing a boundary around a problem has non-technical, or political dimensions, depending on who controls the definition, because someone gains a little power and someone loses a little power.

Step 3 Map what alternative problem definitions mean to different participants. More than likely you will best understand problem definitions that fit your perspective. But ask: does it fit other perspectives as well? Look at those who hold Perspective A. Does your definition fit their location, their knowledge, and their desires? Now turn to those who hold Perspective B. Does your definition fit their location, knowledge, and desires? Completing this step is difficult because it requires stepping outside of one's own perspective and attempting to understand the problem in terms of different perspectives.

Step 4 To the extent you encounter disagreement or conclude that the achievement of it is insufficient, begin asking yourself: How might I adapt my problem definition to take account of other perspectives out there? Is there some way of accommodating myself to other perspectives rather than just demanding that the others simply recognize the inherent value and rationality of mine? Is there room for compromise among contrasting perspectives?

Figure 4. Collaborative problem definition. 
pedagogy helps students make this move by formally expanding the engineering method to include a four-step process for collaborative problem definition prior to the activity of mathematical problem solving. This process includes identifying perspectives, identifying who owns which definitions, mapping what alternative definitions mean to different participants, and then adapting your own definitions to accommodate other perspectives. Further details regarding each step are displayed in Figure 4.

\section{B. Course Offerings}

To date, Engineering Cultures has been taught in 47 semesterlength versions. Formats include lecture/discussion in both large and small classes as well as 100 percent online versions using a combination of the multimedia module presentations and synchronous class meetings via CentraOne software. Because no textbooks exist at present, readings for each module include a combination of academic and popular publications woven together with content gathered and organized through extensive original research. Informal writing has included student responses through online threaded discussions, memos, autobiographical statements, dialogs, proposals, admission and exit tickets, poetry, and essay exams. Formal writing has included research reports, essay summaries and responses, and reflections assignments.

\section{Assessment}

A large number of formative assessment techniques, including the piloting of all materials online and in-class, have taken place over the past five years, and modifications have been made based on these results [39]. The focus of this section is on the summative assessment designed in Summer 2004 to allow us to evaluate the extent to which students attain the three learning outcomes for global competency specified earlier.

The summative assessment included three instruments that map across the learning outcomes: a pre/post multiple choice content assessment to measure learning outcome 1, a pre/post essay exam to measure learning outcome 2, and a final survey to measure learning outcome 3. Data from the final survey also provides additional evidence for learning outcomes 1 and 2. Only students within the given classes that had declared a major in engineering are included in the analyses that follow.

\section{Pre/Post Content Assessment Results}

A pre/post multiple choice content assessment was administered on the first and last days of class in both online and in-class versions

\footnotetext{
1. In France, engineering constitutes an occupation with:

(a) a status roughly equal to artisan workers,

(b) a status below doctors and lawyers,

(c) highest status for those who work in industry,

(d) highest status for those who work in government*
}

2. British engineers traditionally learned to become engineers:

(a) at universities such as Oxford and Cambridge

(b) through apprenticeships supervised by mechanics and engineers*

(c) at middle schools taught by engineering faculty

(d) in factories as salaried employees

Note: Correct answer is indicated by *

Figure 5. Sample pre/post content questions.

\begin{tabular}{ccccccc}
\hline & Semester & $\begin{array}{l}\text { Course } \\
\text { Design }\end{array}$ & n & Pre- & Post- & $\boldsymbol{p}$-value \\
\hline 1. & Fall 04 & In-class & 32 & 14.63 & 18.73 & $<0.05$ \\
2. & Fall 04 & In-class & 34 & 14.49 & 18.88 & $<0.05$ \\
3. & Fall 04 & In-class & 30 & 13.93 & 19.09 & $<0.05$ \\
4. & Spring 05 & Online & 25 & 13.69 & 18.86 & $<0.05$ \\
5. & Spring 05 & Online & 25 & 13.46 & 20.12 & $<0.05$
\end{tabular}

Table 1. Results of pre/post content assessment.

of the course. The courses under investigation were offered at Virginia Tech during Fall 2004 and Spring 2005 and at the Colorado School of Mines during Spring 2005. The fall course was taught as a large classroom section with recitation classes led by graduate teaching assistants. Each section that had a different recitation leader was treated as a distinct course, because students who had different recitation instructors may possibly have had systematically distinct experiences. Also, when the recitation leader taught multiplesections under the same instructor, these were combined as a single course. The spring courses at Virginia Tech were taught online by two of the recitation leaders, and the course at CSM was taught inclass. Questions on the pre/post content assessment were multiple choice and in the format displayed in Figure 5.

To examine if students' content knowledge increased as a result of the course, a one-tailed paired $t$-test was completed on the $\mathrm{pre} / \mathrm{post}$ content assessment results within each course. Since it may be argued that meaningful change requires more than a simple increase from pre to post assessment, we defined meaningful change as an average increase of three points, or the equivalent of a full grade, which would result, on average, in a 12 percent increase.

The results of this analysis, including pre- and post- content assessment means, are displayed in Table 1 . The five courses displayed a significant increase in performance from pre- to post- assessment with a $p$ value less than 0.05 . In the Colorado School of Mines course, the mean of the content assessment increased from 12.63 to 18 . These values could not be analyzed statistically because the data were collected anonymously, preventing the pairing of dependent values. The results do display a comparable positive increase of roughly two letter grades even when the course was taught by a different instructor at a different school. At the same time, the fact that mean scores at the end of the course did not approach 100 percent correct does raise additional questions about students' content knowledge, including the use of multiple choice questions to establish the metric.

\section{E. Pre/Post Essay Assessment Results}

Figure 6 displays an essay question that was administered on the first and last days of class, as well as a scoring rubric for the question. The scoring rubric was developed to guide the grading process and ensure inter-rater reliability. Approximately 20 percent of the student essays were double coded and agreement within each class was consistently 80 percent or better. The pre- and post-essays were scored during the same time period and by the same raters.

Table 2 contains the percentage of students to score within each score category on the pre- and post-essay. As this table indicates, student performance on this essay increased substantially from beginning to end of each course. Noticeable increases occurred in the percentages of students to score in the top score categories and 
Question: As an American engineer, you have been invited by Airbus Industries in Toulouse, France to help design an "environmentally sustainable and socially responsible" manufacturing plant. The design team includes engineers from France, Germany, and United Kingdom because Airbus is jointly owned by companies from those countries. How prepared are you to enter this work situation? What knowledge and capabilities do you have and what do you lack?

Outcome: Be able to explain how national differences among engineers are important in engineering work.

\begin{tabular}{|c|c|c|c|c|}
\hline $\begin{array}{l}\text { Numerical } \\
\text { score }\end{array}$ & $\mathbf{0}$ & 1 & 2 & 3 \\
\hline $\begin{array}{l}\text { Qualitative } \\
\text { assessment }\end{array}$ & Inadequate & $\begin{array}{c}\text { Needs } \\
\text { Improvement }\end{array}$ & Adequate & Excellent \\
\hline Criteria & $\begin{array}{l}\text { The essay } \\
\text { characterizes } \\
\text { engineering work } \\
\text { as entirely } \\
\text { technical, } \\
\text { showing no } \\
\text { awareness of } \\
\text { national } \\
\text { differences among } \\
\text { engineers in } \\
\text { France, Britain, } \\
\text { and/or Germany. }\end{array}$ & $\begin{array}{l}\text { The essay shows } \\
\text { awareness of } \\
\text { differences in } \\
\text { language and } \\
\text { customs among } \\
\text { French, British, } \\
\text { and/or German } \\
\text { engineers but does } \\
\text { not recognize } \\
\text { national differences } \\
\text { related to } \\
\text { engineering work. }\end{array}$ & $\begin{array}{l}\text { The essay } \\
\text { describes national } \\
\text { patterns of } \\
\text { engineering } \\
\text { knowledge and } \\
\text { engineers' } \\
\text { identities in } \\
\text { France, Britain, } \\
\text { and/or Germany } \\
\text { but does not } \\
\text { explain how these } \\
\text { patterns are } \\
\text { important in } \\
\text { engineering work. }\end{array}$ & $\begin{array}{l}\text { The essay } \\
\text { describes national } \\
\text { patterns of } \\
\text { engineering } \\
\text { knowledge and } \\
\text { engineers' } \\
\text { identities in } \\
\text { France, Britain, } \\
\text { and/or Germany } \\
\text { and explains how } \\
\text { these patterns are } \\
\text { important in } \\
\text { engineering work. }\end{array}$ \\
\hline
\end{tabular}

Figure 6. Pre/post essay assignment and scoring rubric.

decreases in the percentages of students to score in the bottom score categories, producing a positive upward shift from pre- to post- assessment. To determine whether a statistically significant change occurred at the top level, a one-tailed $z$-test for proportions was used and this resulted in a $p$-value of less than 0.05 , suggesting a statistically significant increase.

\section{F. Final Survey Results}

Table 3 displays students' responses to an end-of-semester survey that was administered to students in participating classrooms. A core set of questions was used in both the online and in-class versions of the course and several additional questions were asked of students in the online version of the course. Only questions on this survey that were relevant to course outcomes are discussed here.

One section of the survey asks students to indicate their level of agreement with a set of statements. As Table 3 indicates, high percentages of students either "agreed" or "strongly agreed" with each statement. Roughly 94 percent of 176 students agreed that they "gained significant knowledge from this course about engineers, while 97 percent agreed that they are "better prepared to work with engineers from different countries." In addition, 96 percent agreed they "have a better understanding of how my perspective as an engineer is different from those of engineers from other countries" and 92 percent agreed that they will be "better at working with people

\begin{tabular}{|c|c|c|c|c|c|c|c|c|c|c|c|}
\hline & \multirow[b]{2}{*}{$\begin{array}{l}\text { Course } \\
\text { Design }\end{array}$} & \multicolumn{5}{|c|}{ Pre-essay } & \multicolumn{5}{|c|}{ Post-essay } \\
\hline & & $\#$ & $\mathbf{0}$ & 1 & 2 & 3 & $\#$ & $\mathbf{0}$ & 1 & 2 & 3 \\
\hline 1. VT, Fall 04 & $\begin{array}{l}\text { In- } \\
\text { class }\end{array}$ & 31 & $29 \%$ & $68 \%$ & $0 \%$ & $3 \%$ & 31 & $0 \%$ & $7 \%$ & $36 \%$ & $57 \%$ \\
\hline 2. VT, Fall 04 & $\begin{array}{l}\text { In- } \\
\text { class }\end{array}$ & 35 & $20 \%$ & $66 \%$ & $14 \%$ & $0 \%$ & 35 & $3 \%$ & $10 \%$ & $20 \%$ & $67 \%$ \\
\hline 3. VT, Fall 04 & $\begin{array}{l}\text { In- } \\
\text { class }\end{array}$ & 32 & $28 \%$ & $69 \%$ & $3 \%$ & $0 \%$ & 32 & $0 \%$ & $7 \%$ & $32 \%$ & $61 \%$ \\
\hline 4. VT, Sp 05 & On-line & 25 & $16 \%$ & $68 \%$ & $12 \%$ & $4 \%$ & 25 & $0 \%$ & $16 \%$ & $32 \%$ & $52 \%$ \\
\hline 5. VT, Sp 05 & On-line & 25 & $0 \%$ & $96 \%$ & $0 \%$ & $4 \%$ & 25 & $0 \%$ & $16 \%$ & $28 \%$ & $56 \%$ \\
\hline 6. CSM, Sp 05 & $\begin{array}{l}\text { In- } \\
\text { class }\end{array}$ & 29 & $28 \%$ & $59 \%$ & $10 \%$ & $3 \%$ & 24 & $0 \%$ & $0 \%$ & $33 \%$ & $67 \%$ \\
\hline
\end{tabular}

Table 2. Results of pre/postessay assessment. 


\begin{tabular}{|c|c|c|c|c|c|c|c|c|}
\hline \multicolumn{4}{|c|}{$\begin{array}{l}\text { (1) I gained significant knowledge } \\
\text { from this course about engineers in } \\
\text { the world. }\end{array}$} & \multirow{2}{*}{$\begin{array}{c}\text { Strongly } \\
\text { Disagree }\end{array}$} & \multirow{2}{*}{$\begin{array}{l}\text { Disagree } \\
2.78 \%\end{array}$} & \multirow{2}{*}{$\begin{array}{l}\text { Agree } \\
38.89 \%\end{array}$} & \multirow{2}{*}{$\begin{array}{c}\text { Strongly } \\
\text { Agree }\end{array}$} & \multirow{2}{*}{$\begin{array}{l}\mathbf{N} \\
36\end{array}$} \\
\hline 1. & VT & Fall 04 & In-class & & & & & \\
\hline 2. & VT & Fall 04 & In-class & $5.56 \%$ & $2.78 \%$ & $50.00 \%$ & $41.67 \%$ & 36 \\
\hline 3. & VT & Fall 04 & In-class & $3.45 \%$ & $0.00 \%$ & $58.62 \%$ & $37.93 \%$ & 29 \\
\hline 4. & VT & Sp 05 & Online & $12.00 \%$ & $0.00 \%$ & $60.00 \%$ & $28.00 \%$ & 25 \\
\hline 5. & VT & Sp 05 & Online & $4.00 \%$ & $0.00 \%$ & $44.00 \%$ & $52.00 \%$ & 25 \\
\hline \multirow[t]{2}{*}{6.} & CSM & Sp 05 & In-class & $4.00 \%$ & $0.00 \%$ & $52.00 \%$ & $44.00 \%$ & 25 \\
\hline & & & Total & $5.11 \%$ & $1.14 \%$ & $50.00 \%$ & $43.75 \%$ & 176 \\
\hline
\end{tabular}

(2) I am better prepared to meet and work with engineers from different countries.

$\begin{array}{lccllllll}\text { 1. } & \text { VT } & \text { Fall 04 } & \text { In-class } & 2.78 \% & 2.78 \% & 47.22 \% & 47.22 \% & 36 \\ \text { 2. } & \text { VT } & \text { Fall 04 } & \text { In-class } & 2.78 \% & 2.78 \% & 52.78 \% & 41.67 \% & 36 \\ \text { 3. } & \text { VT } & \text { Fall 04 } & \text { In-class } & 0.00 \% & 0.00 \% & 58.62 \% & 41.38 \% & 29 \\ \text { 4. } & \text { VT } & \text { Sp 05 } & \text { Online } & 0.00 \% & 0.00 \% & 64.00 \% & 36.00 \% & 25 \\ \text { 5. } & \text { VT } & \text { Sp 05 } & \text { Online } & 4.00 \% & 0.00 \% & 48.00 \% & 48.00 \% & 25 \\ \text { 6. } & \text { CSM } & \text { Sp 05 } & \text { In-class } & 0.00 \% & 4.00 \% & 56.00 \% & 40.00 \% & 25 \\ & & & \text { Total } & 1.70 \% & 1.70 \% & 53.98 \% & 42.61 \% & 176\end{array}$

(3) I now have a better understanding of how my perspective as an engineer is different from those of engineers from other countries.

$\begin{array}{lcccccccc}\text { 1. } & \text { VT } & \text { Fall } 04 & \text { In-class } & 5.76 \% & 2.78 \% & 41.67 \% & 50.00 \% & 36 \\ \text { 2. } & \text { VT } & \text { Fall 04 } & \text { In-class } & 0.00 \% & 2.78 \% & 55.56 \% & 41.67 \% & 36 \\ \text { 3. } & \text { VT } & \text { Fall } 04 & \text { In-class } & 3.45 \% & 0.00 \% & 58.62 \% & 37.93 \% & 29 \\ \text { 4. } & \text { VT } & \text { Sp 05 } & \text { Online } & 4.00 \% & 0.00 \% & 56.00 \% & 40.00 \% & 25 \\ \text { 5. } & \text { VT } & \text { Sp 05 } & \text { Online } & 0.00 \% & 0.00 \% & 56.00 \% & 44.00 \% & 25 \\ \text { 6. } & \text { CSM } & \text { Sp 05 } & \text { In-class } & 0.00 \% & 4.00 \% & 44.00 \% & 52.00 \% & 25 \\ & & & \text { Total } & 2.27 \% & 1.70 \% & 51.70 \% & 44.32 \% & 176\end{array}$

(4) I will now be better at working with people who define problems differently than I do.

$\begin{array}{lcccccccc}\text { 1. } & \text { VT } & \text { Fall 04 } & \text { In-class } & 5.56 \% & 5.56 \% & 55.56 \% & 33.33 \% & 36 \\ \text { 2. } & \text { VT } & \text { Fall 04 } & \text { In-class } & 8.33 \% & 0.00 \% & 61.11 \% & 30.56 \% & 36 \\ \text { 3. } & \text { VT } & \text { Fall 04 } & \text { In-class } & 3.45 \% & 6.90 \% & 55.17 \% & 34.48 \% & 29 \\ \text { 4. } & \text { VT } & \text { Sp 05 } & \text { Online } & 8.00 \% & 0.00 \% & 68.00 \% & 24.00 \% & 25 \\ \text { 5. } & \text { VT } & \text { Sp 05 } & \text { Online } & 0.00 \% & 4.00 \% & 64.00 \% & 32.00 \% & 25 \\ \text { 6. } & \text { CSM } & \text { Sp 05 } & \text { In-class } & 0.00 \% & 4.00 \% & 64.00 \% & 32.00 \% & 25\end{array}$

Table 3. Results offinal survey assessment (continues). 
(5) After learning about engineering and engineers in the world, I will now be more likely to have a satisfying career as an engineer.

\begin{tabular}{ccccccccc} 
1. & VT & Fall 04 & In-class & $5.56 \%$ & $13.89 \%$ & $61.11 \%$ & $19.44 \%$ & 36 \\
2. & VT & Fall 04 & In-class & $2.78 \%$ & $8.33 \%$ & $77.78 \%$ & $11.11 \%$ & 36 \\
3. & VT & Fall 04 & In-class & $0.00 \%$ & $6.90 \%$ & $79.31 \%$ & $13.79 \%$ & 29 \\
4. & VT & Sp 05 & Online & $4.00 \%$ & $8.00 \%$ & $72.00 \%$ & $16.00 \%$ & 25 \\
5. & VT & Sp 05 & Online & $0.00 \%$ & $8.00 \%$ & $80.00 \%$ & $12.00 \%$ & 25 \\
6. & CSM & Sp 05 & In-class & $0.00 \%$ & $20.00 \%$ & $64.00 \%$ & $16.00 \%$ & 25 \\
& & & Total & $2.27 \%$ & $10.80 \%$ & $72.16 \%$ & $14.77 \%$ & 176 \\
\hline
\end{tabular}

Table 3. (continued).

who define problems differently than I do.” A somewhat smaller number, 87 percent, agreed that they will now "be more likely to have a satisfying career as an engineer."

While the student self-reports support the findings for learning outcomes 1 and 2 , their significance lies more in providing evidence for learning outcome 3 , development of a predisposition to engage engineers from other countries as co-workers who have knowledge and value. That is, the high levels of agreement suggest that students are aware both that engineers who define problems differently than they do exist in different countries and that it is important to engage such engineers as co-workers who have knowledge and value. The smaller number agreeing that they are more likely to have a satisfying career as an engineer perhaps indicates the limited reach of a single undergraduate course.

\section{G. Limitations and Future Plans}

The major limitations of Engineering Cultures are derived from its status as a single, elective course. First, no quantitative evidence exists indicating how long the achieved competencies in the course remain salient in the careers of students. We do not know, for example, the extent to which participating in Engineering Cultures attracted students to seek additional methods for enhancing global competency or to pursue international work. Plans to pursue this as a research question are underway and will be investigated through a longitudinal survey of the more than 2,000 students who have completed the course over the past decade.

Second, the one-semester length of the course limits student learning to an introduction to the emergence of engineering in five or six countries, along with associated exercises and simulations. At CSM, a follow-up course has been developed called Engineering Cultures in the Developing World. Also, in conjunction with the Practical Reasoning Seminar at the Carnegie Foundation for the Advancement of Teaching, work has begun on the Engineering Engagements project, case studies of conflicts in engineering problem definition that will provide materials for a practically-oriented follow-up course. A significant feature of the Engineering Engagements project is that it seeks to document conflicts in problem definition owing not only to national differences but also differences in professional training and organizational position.

Third, the tightly-structured syllabus for Engineering Cultures was originally not designed to be partitioned and used by humani- ties/social science or engineering faculty as supplements to other courses. However, multimedia versions of Engineering Cultures modules have been developed and placed on the Web for this purpose [40]. These modules may also be useful as refresher courses for former students.

\section{SUMMARY AND CONCLUSIONS}

A key benefit of the learning criterion for global competency presented in this paper is to call attention to the importance of working effectively with people who define problems differently, including both engineers and non-engineers. The often-stated goal of learning to work productively with other cultures involves going beyond recognizing that engineering problems can be solved in different ways, to understanding that engineering problems can be defined in different ways. While it is now inappropriate to assume that each person is a member of one culture whose boundaries coincide with those of a country, it is still critically important for students to gain educational and work experiences with people who were raised and trained in other countries and to understand dominant images and patterns of engineering work in those countries. Such people remain most likely to draw boundaries around problems in different ways and to judge problems to have different sorts of implications for their lives and careers. In addition, developing the ability to anticipate, understand, and respect perspectives that originate far from home can make it easier to understand conflicting perspectives closer to home as the product of legitimate differences.

By calling attention to practices of problem definition in collaboration with others, the acquisition of global competency also makes more visible what might be called the "other half" of engineering work, i.e., the non-technical human dimensions of engineering work, which stand alongside the technical dimensions as essential core features. Globally competent engineers may also achieve an important skill in quality leadership, the ability to listen. By acquiring global competency, engineers may thus be taking steps to prepare themselves for leadership positions.

As illustrated by the typology of methods for achieving global competency, the main existing approaches to global competency in engineering require international travel. Since international travel can be expensive, those students who choose it must both be able to afford 
it and be willing to undertake it. Because such willingness indicates an expectation that the trip will be of value, it presupposes a prior step toward the achievement of global competency. That presupposition could prove to be a difficult barrier to scaling up such methods.

Accordingly, we are led ultimately to advocate a dramatic expansion in integrated class experiences for engineering students to help them take the critical first step toward global competency. Engineering Cultures provides one example of an approach that appears to have been successful, at least in the short run. Indeed, the easy adaptability of the elective course makes it an obvious place for integrating the pursuit of global competency onto the transcripts of engineering students. But the ultimate success of methods for achieving global competency will depend both upon their integration across the full range of the engineering curriculum, including engineering science courses, and upon widespread acceptance among engineering educators of the importance of giving as much weight and time to problem definition as is currently given to problem solving.

\section{ACKNOWLEDGMENTS}

Gary Downey, Juan Lucena, and Barbara Moskal would like to acknowledge grant support from NSF \# DUE 0230992. Downey and Lucena also want to acknowledge support from the Center for Innovation in Learning and Video Broadcast Services at Virginia Tech. This article was completed while Downey and Lucena were Boeing Company Fellows in Engineering Education at the U.S. National Academy of Engineering. They express their appreciation for this support. Downey thanks the Research in Engineering Studies group at Virginia Tech for their comments on a previous draft, and fellow participants in the Cross-Professions Seminar at the Carnegie Foundation for the Advancement of Teaching, which is currently analyzing practical reasoning in pedagogies of the liberal arts and professions. Finally, the authors collectively thank the editor as well as the anonymous associate editor and reviewers for their thorough review of this manuscript. The gift of their detailed, dedicated work has significantly improved the quality of this contribution to research in engineering education.

\section{REFERENCES}

[1] Hunter, W. D., "Got Global Competency?," International Educator, Spring, 2005, pp. 6-12.

[2] Curran, K., "Global Competencies That Facilitate Working Effectively Across Cultures," http://content.monster.com.sg/management/5808, 2003.

[3] Lambert, R., "Parsing The Concept of Global Competence," Educational Exchange and Global Competence, Council on International Educational Exchange: New York, New York, 1996.

[4] Swearengen, J.C., Barnes, Spencer, Coe, Steven, Reinhardt, Carsten, and Subramanian, B., "Globalization and The Undergraduate Manufacturing Engineering Curriculum," Journal of Engineering Education, Vol. 91, No. 2, 2002, pp. 255-261.

[5] Chaturvedi, S., et al., "Global Engineering in an Interconnected World: An Upper Division General Education Cluster at Old Dominion University," (CD) Proceedings, 2001 ASEE Annual Conference and Exposition, American Society for Engineering Education.

[6] DiBiasio, D., and S. Jiusto, "Nontraditional Learning Environments: Do They Prepare Our Students for Life-Long Learning?" (CD)
Proceedings, 2005 ASEE Annual Conference and Exposition, American Society for Engineering Education.

[7] DiBiasio, D., and N.A. Mello, "Multi-Level Assessment of Program Outcomes: Assessing a Nontraditional Study Abroad Program in the Engineering Disciplines," Frontiers: The Interdisciplinary Journal of Study Abroad, Vol. 10, Fall, 2004, pp. 237-252.

[8] Mello, N.A., "How One Institution Provides a Global Perspective for Engineers," (Web) Proceedings, 2001 Frontiers in Education Conference, http://fie.engrng.pitt.edu/fie2001/, Institute of Electrical and Electronic Engineers.

[9] Eljamal, M.B., S.W. Pang, and S.J. Edington, "Gaining International Competence: A Multi-Faceted Approach to International Engineering Education," (CD) Proceedings, 2005 ASEE Annual Conference and Exposition, American Society for Engineering Education.

[10] Bennett, M.J., "Towards Ethnorelativism: A Developmental Model of Intercultural Sensitivity," Education for the Intercultural Experience, R.M. Paige, Editor, Intercultural Press: Yannouth, Maine, 1993.

[11] Mayhewu, M., et al., "Outcomes Assessment in International Engineering Education: Creating a System to Measure Intercultural Development," (CD) Proceedings, 2005 ASEE Annual Conference and Exposition, American Society for Engineering Education.

[12] Downey, G. and J.C. Lucena, "Engineering Selves," Cyborgs and Citadels: Antbropological Interventions in Emerging Sciences and Technologies, Gary L. Downey et al., Editor, University of Washington Press: Seattle, Washington, 1996, pp. 117-142.

[13] Brody, H., "The Political Pleasures of Engineering: An Interview with John Sununu," Technology Review, Vol 95, No. 6, 1992, pp. $22-28$.

[14] Downey, G.L., and J.C. Lucena, "Knowledge and Professional Identity in Engineering: Code-Switching and the Metrics of Progress," History and Technology, Vol. 20, No. 4, 2004, pp. 393-420.

[15] Downey, G.L., and J.C. Lucena, "When Students Resist: Ethnography of a Senior Design Experience in Engineering Education," International Journal of Engineering Education, Vol. 19, No. 1, 2003, pp. 168-176.

[16] Dym, C.L., "Special Issue: Social Dimensions of Engineering Design," International Journal of Engineering Education, Vol. 19, No. 1, 2003.

[17] Seliger, G., "Global Product Development (GPD): A Global Lecture on Design and Manufacturing of Global Products," Proceedings, Enhancing Engineering Education in Europe (E 4) Innovations in Engineering Education, "Challenges, Concepts and Good Practice," 2004.

[18] SEFI, The Bologna Declaration and Engineering Education-a Discussion Paper, Brussels, Belgium: European Society for Engineering Education, 2002.

[19] Yeargan, J., and K. Hernaut, "The Globalization of European Engineering Education: An American Observer's Perspective," (Web) Proceedings, 2001 Frontiers in Education Conference, http://fie.engrng.pitt.edu/ fie2001/, Institute of Electrical and Electronic Engineers.

[20] Soeiro, A., "European Experience in Engineering Education and Accreditation," Proceedings, ASEE 4th Global Colloquium on Engineering Education, American Society for Engineering Education, 2005.

[21] Kolmos, A., "Transformation of Problem Based Learning in Engineering Education," Proceedings, ASEE 4th Global Colloquium on Engineering Education, American Society for Engineering Education, 2005.

[22] Saunders-Smits, G.N., and E. de Graaff, "The Development of Integrated Professional Skills in Aerospace Engineering Through Problem-Based Learning in Design Projects," (CD) Proceedings, 2003 ASEE Annual Conference E Exposition, American Society for Engineering Education. 
[23] Montoya, R., "The Anglo-Saxon Model for Engineering Education: A Feasible Alternative for Colombia?" (CD) Proceedings, 2004 ASEE Annual Conference and Exposition, American Society for Engineering Education.

[AVP2] [24] Downey, G.L. and J.C. Lucena, Interview with Ruth Walters, EPF, Sceaux, France, 2001.

[AVP3] [25] Legg, G., "American Engineers in Japan: Same Profession, Different World," EDN, Vol. 34, No. 22, 1989, pp. 59-66.

[AVP4] [26] Legg, G., "American Engineers in Japan: Getting By With A Little Help From Their Friends," EDN, Vol. 34, No. 23, 1989, pp. 67-72.

[27] Downey, G.L., "Are Engineers Losing Control of Technology?: From 'Problem Solving' to 'Problem Definition and Solution' in Engineering Education," Chemical Engineering Research and Design, Vol. 83, No. A8, 2005, pp. 1-12.

[28] Shuman, L.J., M. Besterfield-Sacre, and J. McGourty, "The ABET 'Professional Skills'-Can They be Taught? Can They be Assessed?” Journal of Engineering Education, January, 2005, pp. 41-55.

[29] Carnegie Foundation for the Advancement of Teaching, Rethinking the Life of the Mind for Practice: A Research Seminar on Professional and Liberal Education, Stanford, California: Carnegie Foundation, http://www. carnegiefoundation.org/PPP/seminar.htm, 2005.

[30] Rosin, M.S., and W.M. Sullivan, The Encounter of Practical with Technical Reasoning, Stanford, California: Carnegie Foundation for the Advancement of Teaching, in preparation.

[31] National Science Foundation, Developing Global Scientists and Engineers: Program Solicitation 04-036, Arlington, Virginia: NSF, 2004.

[32] Lohmann, J., "Georgia Tech's Strategies for Global Engineers," Proceedings, Conference on Enhancement of the Global Perspective for Engineering Students by Providing an International Experience, Engineering Conferences International, 2003.

[33] Gerhardt, L.A., P. Blumenthal, and S. Spodek, "Educating the Global Engineer: A Program to Promote Study Abroad, International Exchanges and Diversity in Undergraduate Engineering," (CD) Proceedings, 2002 ASEE Annual Conference E' Exposition, American Society for Engineering Education.

[34] Dolby, N., "Encountering an American Self: Study Abroad and National Identity," Comparative Education Review, Vol. 48, No. 2, 2004, pp. 150-173.

[35] Davis, M., Open Doors 2003: Report of International Education, New York, New York: Institute for International Education, http://www. opendoorsweb.org, 2003.

[36] Hannesson, S., Email communication with ERASMUS officer on European engineering students participating in international education, 2005.

[37] Downey, G.L., "Anxious by Definition: American Engineers and Low Cost, Mass Use." History and Technology, forthcoming 2006.

[38] Lucena, J.C., "De Criollos a Mexicanos: Engineers' Identity and the Construction of Mexico," History and Technology, forthcoming 2006.

[39] Downey, G.L., et al., "Engineering Cultures: Expanding the Engineering Method for Global Problem Solvers," Proceedings, ASEE 4th Global Colloquium on Engineering Education, American Society for Engineering Education, 2005.

[40] www.conted.vt.edu/ecs.

\section{AUTHORS' BIOGRAPHIES}

Gary Downey is professor of Science and Technology Studies and affiliated faculty member in the Department of Engineering Education at Virginia Tech. He is also 2005-2006 Boeing Compa- ny Senior Fellow in Engineering Education at the U.S. National Academy of Engineering and was keynote lecturer on the engineer as problem definer at the 7th World Congress of Chemical Engineering at Glasgow, Scotland. Trained as a mechanical engineer (B.S. Lehigh University, 1974) and cultural anthropologist (Ph.D. University of Chicago, 1981), he is winner of Virginia Tech's 1997 Diggs Teaching Scholar Award for scholarship in teaching, 2003 XCaliber Award for instructional technology, and 2004 William E. Wine Award for career excellence in teaching. He is author of The Machine in Me: An Anthropologist Sits Among Computer Engineers (Routledge 1998) and co-developer of Engineering Cultures ${ }^{\circledR}$ multimedia courseware.

Address: Department of Science and Technology in Society, Virginia Tech, Blacksburg, Virginia 24061-0247; telephone: (+1)540.231.4761; fax: (+1)540.231.7013; e-mail: downeyg@vt. edu.

Juan Lucena is associate professor in Liberal Arts and International Studies and affiliated faculty member in the Center for Engineering Education at the Colorado School of Mines. He is also 2005-2006 Boeing Company Senior Fellow in Engineering Education at the U.S. National Academy of Engineering and was keynote lecturer at the 2004 National Conference on Engineering Education in Colombia. Trained in mechanical and aeronautical engineering (B.S. Rensselaer Polytechnic Institute, 1987, 1988) and in Science and Technology Studies (Ph.D. Virginia Tech, 1996), he is Principal Investigator of the NSF-funded project Enhancing Engineering Education through Humanitarian Ethics, which is developing a graduate curriculum in humanitarian engineering at CSM. He is author of Defending the Nation: U.S. Policymaking in Science and Engineering Education from Sputnik to the War against Terrorism (University Press of America 2005) and codeveloper of Engineering Cultures( $r$ ) multimedia courseware

Address: Liberal Arts and International Studies, Colorado School of Mines, Golden, Colorado 80401; telephone: (+1)303.273.3564; fax: (+1)303.273.3751; e-mail: jlucena@ mines.edu.

Barbara M. Moskal is associate professor in the Mathematical and Computer Sciences Department at the Colorado School of Mines. She received her Ed.D. in Mathematics Education with a minor in Quantitative Research Methodology and her M.A. in Mathematics from the University of Pittsburgh. Her research interests include student assessment, secondary education outreach, and equity issues in mathematics, science and engineering. She has taught Engineering Calculus I, II and III, Probability and Statistics for Engineers and Differential Equations for Engineers. In 2000, she received a New Faculty Fellowships at the Frontiers in Education Conference. More recently, she received the Alfred E. Jenni Fellowship (2004) for institution-wide contributions to teaching effectiveness and educational scholarship at CSM. The Jenni Fellowship is CSM's most prestigious educational award.

Address: Mathematical and Computer Sciences, Colorado School of Mines, Golden, Colorado 80401; telephone: (+1)303.273.3867; fax: (+1)202.273.3875; e-mail: bmoskal@mines. edu.

Thomas Bigley, a Ph.D. candidate in Science and Technology Studies at Virginia Tech, is currently researching technology, identity, and Occidentalism in East/West relations. He teaches courses 
in Science and Technology Studies, including Engineering Cultures. He received B.S./B.L.A./B.E.D. degrees from the University of Minnesota, M.B.A. from Fordham University, J.D. from the William Mitchell College of Law, M.Eng. in Civil and Environmental Engineering from the University of California, Berkeley, with an MA in International and Area Studies from the University of California, Berkeley pending.

Address: Department of Science and Technology in Society, Virginia Tech, Blacksburg, Virginia 24061-0247; telephone: (+1)540.231.9123; fax: (+1)540.231.7013; e-mail: tbigley@vt.edu.

Chris Hays, a Ph.D. student in Science and Technology Studies at Virginia Tech, received her B.A. in biology from Oakland University (1980) and M.S. in biochemistry from Virginia Tech (1985). She has taught or assisted with courses in Science and Technology Studies and in the biological and biochemical sciences; facilitated environmental, gender, and racism awareness programs; and coordinated public educational forums on science, technology, and society. Currently she is researching medical/cultural paradigms of disease and illness.

Address: Department of Science and Technology in Society, Virginia Tech, Blacksburg, Virginia 24061-0247; telephone 540-2317007; fax 540-231-7013; email: chays@vt.edu

Brent K. Jesiek received his B.S. in Electrical Engineering from Michigan Tech in 1998, and entered the Science and Technology Studies program at Virginia Tech in 2001. He received his M.S. in 2003, and is now pursuing his doctoral degree. In addition to serving as a Fellow with Virginia Tech's Graduate Education Development Institute (GEDI), Brent teaches in Science and Technology Studies. His current research is on the history of computer engineering.

Address: Department of Science and Technology in Society, Virginia Tech, Blacksburg, Virginia 24061-0247; telephone: (+1)540.231.7897; e-mail: bjesiek@vt.edu.

Liam Kelly is pursuing a Ph.D. in Science and Technology Studies at Virginia Tech. After completing his B.A. in English and Studio Art at the College of Wooster 1997, he spent five years working as a programmer for a major software firm. He entered the STS program in 2002 and completed his M.S. in Science and Technology Studies in 2004.

Address: Department of Science and Technology in Society, Virginia Tech, Blacksburg, Virginia 24061-0247; telephone: (+1)540.231.7897; e-mail: 1kelly@vt.edu.

Jane L. Lehr is a Research Associate at the Center for Informal Learning and Schools, a National Science Foundation Center for Teaching and Learning at King's College London, UC Santa Cruz, and the Exploratorium (ESI-0119787). She is also a PhD Candidate in Science \& Technology Studies at Virginia Tech. Her research analyzes the intersection of science education and non- scientist citizenship from a feminist and equity-oriented perspective. She is the 2003 recipient of an Outstanding Graduate Student Award at Virginia Tech in recognition of her commitment to social justice work as a teacher, researcher, and community organizer and teaches courses in Women's Studies, Science and Technology Studies, and the Social Foundations of Education.

Address: Department of Education \& Professional Studies, King's College London, Franklin Wilkins Building, 150 Stamford Street, London England SE1 9NH; telephone: $(+44) 207.848 .3780$; fax: (+44)207.848.3182; e-mail: jane.lehr@kcl.ac.uk.

Jonson Miller, a graduate student in Science and Technology Studies at Virginia Tech, is currently researching gender, race, and citizenship in early U.S. engineering education. He teaches courses in Women's Studies and Science and Technology Studies, including history of engineering courses. He received the B.S. in geology (1998) from West Virginia University and M.S. in geology (2000) from the University of Wisconsin.

Address: Department of Science and Technology in Society, Virginia Tech, Blacksburg, Virginia 24061-0247; telephone: (+1)540.231.9123; fax: (+1)540.231.7013; e-mail: jonson@vt. edu.

Amy Nichols-Belo received her B.A. in International Affairs and History at James Madison University in 1998 and her M.S. in Science and Technology Studies at Virginia Tech in 2002. She is now a Ph.D. candidate in cultural anthropology at the University of Virginia.

Address: c/o Department of Science and Technology in Society, Virginia Tech, Blacksburg, Virginia 24061-0247; telephone: (+1)540.231.9123; fax: (+1)540.231.7013; e-mail: abn5v@ virginia.edu.

Sharon Ruff, a Ph.D. student in Science and Technology Studies at Virginia Tech. She is currently researching gender and engineering and teaching Engineering Cultures. She received her B.S. in mathematics (2000) from Penn State University.

Address: Department of Science and Technology in Society, Virginia Tech, Blacksburg, Virginia 24061-0247; telephone: (+1)540.231.9263; fax: (+1)540.231.7013; e-mail: sruff@vt.edu.

Rosamond S. Parkhurst is a graduate student in the Mathematical and Computer Sciences Department at the Colorado School of Mines. She received her B.S. in Mathematical and Computer Sciences with an area of special interest in Engineering from CSM. In 2002 she received the Boettcher Scholarship, a prestigious scholarship awarded to forty students in Colorado each year. Selection criteria include scholastic achievement, leadership and involvement, service to community and school, and outstanding character. Currently she is involved in an outreach program to integrate engineering into the middle school classroom.

Address: Mathematical and Computer Sciences, Colorado School of Mines, Golden, Colorado 80401; telephone: (+1)303.273.3860; e-mail: rshaffer@mines.edu. 


\section{Author QueRIEs}

Title: The Globally Competent Engineer: Working Effectively with People Who Define Problems Differently

Authors: Gary Lee Downey, Juan C. Lucena, Barbara M. Moskal, Rosamond Parkhurst, Thomas Bigley, Chris Hays, Brent K. Jesiek, Liam Kelly, Jonson Miller, Sharon Ruff, Jane L. Lehr, Amy Nichols-Belo

[AVP1]Need all authors

[AVP2]Spell out EPF

[AVP3]Spell out EDN

[AVP4]Spell out EDN 